University of Massachusetts Amherst

ScholarWorks@UMass Amherst

1999

\title{
Identification of the principal selenium compounds in selenium-enriched natural sample extracts by ion-pair liquid chromatography with inductively coupled plasma- and electrospray ionization-mass spectrometric detection
}

M Kotrebai

M Birringer

JF Tyson

E Block

PC Uden

Follow this and additional works at: https://scholarworks.umass.edu/chem_faculty_pubs

\section{Recommended Citation}

Kotrebai, M; Birringer, M; Tyson, JF; Block, E; and Uden, PC, "Identification of the principal selenium compounds in seleniumenriched natural sample extracts by ion-pair liquid chromatography with inductively coupled plasma- and electrospray ionization-mass spectrometric detection" (1999). Analytical Communications. 1055.

Retrieved from https://scholarworks.umass.edu/chem_faculty_pubs/1055 


\title{
Identification of the principal selenium compounds in selenium-enriched natural sample extracts by ion-pair liquid chromatography with inductively coupled plasma- and electrospray ionization-mass spectrometric detection
}

\author{
Mihály Kotrebai, ${ }^{a}$ Marc Birringer, ${ }^{b}$ Julian F. Tyson, ${ }^{a}$ Eric Block $^{b}$ and Peter C. Uden*a \\ a Department of Chemistry, Lederle Graduate Research Tower A, University of \\ Massachusetts, Box 35410, Amherst, MA 01003-4510, USA \\ ${ }^{b}$ Department of Chemistry, SUNY-Albany, Albany, NY 12222, USA
}

Received 7th April 1999, Accepted 13th May 1999

\begin{abstract}
Selenium-enriched garlic and yeast sample extracts and digests were analyzed using ion-pair high performance liquid chromatography (HPLC) with on-line inductively coupled plasma-mass spectrometric (ICP-MS) and electrospray ionization-mass spectrometric (ESI-MS) detection. The principal selenium compounds in these samples were identified as selenomethionine, and Se-adenosyl-selenohomocysteine in yeast, and $\gamma$-glutamyl-Se-methyl-selenocysteine and possibly $\gamma$-glutamyl-selenomethionine in garlic. The compounds identified account for 85 and $90 \%$ of the total selenium content of the yeast and the garlic samples, respectively. On-line HPLC-ESI-MS selected ion chromatograms (SIC) and mass spectra of selenium compounds extracted from selenium enriched samples are presented. Limits of quantification (LOQ, defined as $S / N=10$ ) for HPLC-ICP-MS were in the range 10-50 $\mathrm{ng} \mathrm{mL}^{-1} \mathrm{Se}$ in the injected extracts. LOQ values for HPLC-ESI-MS were $c a$. 100 times higher than those of HPLC-ICP-MS.
\end{abstract}

\section{Introduction}

The importance of selenium in human nutrition and in cancer chemo-prevention has been demonstrated, ${ }^{1-3}$ directing a major interest from the analytical community towards the separation and identification of selenium compounds in various matrices. ${ }^{4-7}$ The techniques employed have mainly been capable of identifying the presence of selenium compounds without providing structural information, thus leaving retention time matching of available standards as the major form of identification. Recently heart-cutting and preconcentration were employed to obtain a high enough concentration for off-line electrospray ionization-mass spectrometric (ESI-MS) analysis to identify Se-adenosyl-selenohomocysteine as the major selenium compound in the water extract of a selenium-enriched yeast sample. ${ }^{8}$ On-line ESI-MS identification was reported by Momplasir et al. ${ }^{9}$ Detailed reference lists of different existing methods for selenium compound separation are available from earlier publications. $6,10-12$

The importance of the extraction method employed must also be noted, since the selenium compounds can exist in a free form or are covalently bound in proteins. Thus, by employing simple water extraction, only the free selenium compounds will be detected, thus leading to incomplete differentiation of identified compounds into major and minor categories. As demonstrated in our earlier work, establishing a selenium mass balance is important. ${ }^{6}$ To release the covalently bound selenoamino acids, enzymatic or acidic hydrolysis is necessary. This is especially important for yeast in which selenomethionine was found to be the major component after hydrolysis, but only a minor component after simple hot water extraction. ${ }^{11}$ The reason for this is that the selenomethionine is incorporated into the proteins in place of methionine, which results in undesirable accumulation of selenium following ingestion of seleniumenriched yeast supplements. ${ }^{13}$

\section{Experimental}

\section{Instrumentation}

An Elan 5000 inductively coupled plasma mass spectrometer (Perkin-Elmer Sciex, Thornhill, Ontario, Canada) was used as the detector for HPLC-ICP-MS. Samples were introduced by a Meinhard nebulizer with an in-house fabricated spray chamber containing an impact bead. ${ }^{12}$ The spray chamber had a path length of $8.4 \mathrm{~cm}$ and a volume of $14 \mathrm{~mL}$. The ICP-MS parameter settings were as follows: forward power $1003 \mathrm{~W}$; plasma argon flow $15 \mathrm{~L} \mathrm{~min}^{-1}$; auxiliary argon flow $0.8 \mathrm{~L}$ $\mathrm{min}^{-1}$; nebulizer flow $0.860-1.060 \mathrm{~L} \mathrm{~min}^{-1}$ (optimized daily); nickel sampler and skimmer cones; normal resolution; peak hop mode; and dwell time $250 \mathrm{~ms}$. The selenium signal at $\mathrm{m} / \mathrm{z}=82$ was monitored without krypton correction.

The chromatographic system consisted of a liquid chromatographic pump (SP8810, Spectra-Physics, San Jose, CA, USA) and a $5 \mu \mathrm{m}$ Symmetry Shield RP8 $(3.9 \mathrm{~mm} \times 15 \mathrm{~cm})$ column (Waters Corporation, Milford, MA, USA). The column was connected to the nebulizer with PEEK ${ }^{\circledR}$ tubing $(30 \mathrm{~cm} \times 0.25$ $\mathrm{mm}$ id). The mobile phase composition was $99+1(\mathrm{v} / \mathrm{v})$ watermethanol with $0.1 \%$ trifluoroacetic acid. ${ }^{11}$ The mobile phase flow rate was typically $1.0 \mathrm{~mL} \mathrm{~min}-1$ and the sample injection volume was $20 \mu \mathrm{L}$.

A Bruker-Hewlett Packard Esquire-LC Mass Spectrometer (Bruker-Franzen Analytik Gmbh, Bremen, Germany) was used for the molecular mass spectral studies. For HPLC-MS analysis the $1 \mathrm{~mL} \mathrm{~min}{ }^{-1}$ column output was split in a $1: 5$ ratio wtih a $\mathrm{T}$ flow splitter. The column was connected to the ESI source with PEEK $^{\circledR}$ tubing $(8 \mathrm{~cm} \times 0.25 \mathrm{~mm}$ id). Mass calibration and optimizing of the operating parameters were performed daily and generally followed the manufacturer's guidelines.

\section{Chemicals}

Barnstead E-pure 18 Mohm water (Boston, MA, USA), hydrochloric acid (purified by sub-boiling), trifluoroacetic acid (Aldrich, Milwaukee, WI, USA) and methanol (HPLC grade) were used.

DL-Selenomethionine, and Protease XIV, were obtained from Sigma (St. Louis, MO, USA). Se-Adenosyl-DL-selenohomocysteine and $\gamma$-glutamyl-Se-methyl-L-selenocysteine were synthesized in-house. Selenium-enriched yeast (1922 $\mu \mathrm{g}$ Se per g dry sample) was obtained from Nutrition 21 (San Diego, CA, USA), 
Dr Helen Crews (Norfolk and Norwich Hospital, Norwich, UK), and Dr Richard Zitomer (State University of New York, Albany, NY, USA). Selenium-enriched garlic (296 $\mu \mathrm{g}$ Se per g dry sample) was from Dr Clement Ip (Rsowell Park Cancer Institute, Buffalo, NY, USA). Stock solutions of selenoamino acids were prepared in $0.2 \mathrm{M} \mathrm{HCl}$. All solutions were stored in the dark at $0-4{ }^{\circ} \mathrm{C}$.

\section{Sample preparation}

The enzymatic digestion and hot water extractions followed the procedures reported earlier, ${ }^{6}$ and they are only briefly summarized here. For the hot water extraction, $5 \mathrm{~mL}$ distilled deionized water was added to $0.2 \mathrm{~g}$ sample in $15 \mathrm{~mL}$ centrifuge tube and the tube was placed in a double, boiling water bath for an hour. The mixture was shaken well every $15 \mathrm{~min}$. For the enzymatic digestion, $5 \mathrm{~mL}$ distilled deionized water was added to $0.2 \mathrm{~g}$ sample and $0.02 \mathrm{~g}$ 'Protease XIV' enzyme in a $15 \mathrm{~mL}$ centrifuge tube, and shaken for $24 \mathrm{~h}$ at room temperature. For the preparation of the concentrated extracts, the original sample to water ratio $(0.2 \mathrm{~g}: 5 \mathrm{~mL})$ was increased 5-fold. After the extraction, the samples were centrifuged and filtered.

\section{Results and discussion}

\section{HPLC-ICP-MS analysis}

Figs. 1A and B show the on-line HPLC-ICP-MS chromatograms of selenium-enriched yeast and garlic, respectively. The somewhat poorer separation at the beginning of the chromatogram, as compared to our earlier work, using $0.1 \%$ TFA in the mobile phase, ${ }^{6}$ is due to the change of the column from a Zorbax SB-C8 $(4.6 \mathrm{~mm} \times 15 \mathrm{~cm})$ to a Symmetry Shield RP8 $(3.9 \mathrm{~mm}$ $\times 15 \mathrm{~cm}$ ). The latter has a polar modifier group between the silica base and the $\mathrm{C} 8$ group ${ }^{14}$ and the advantages of the

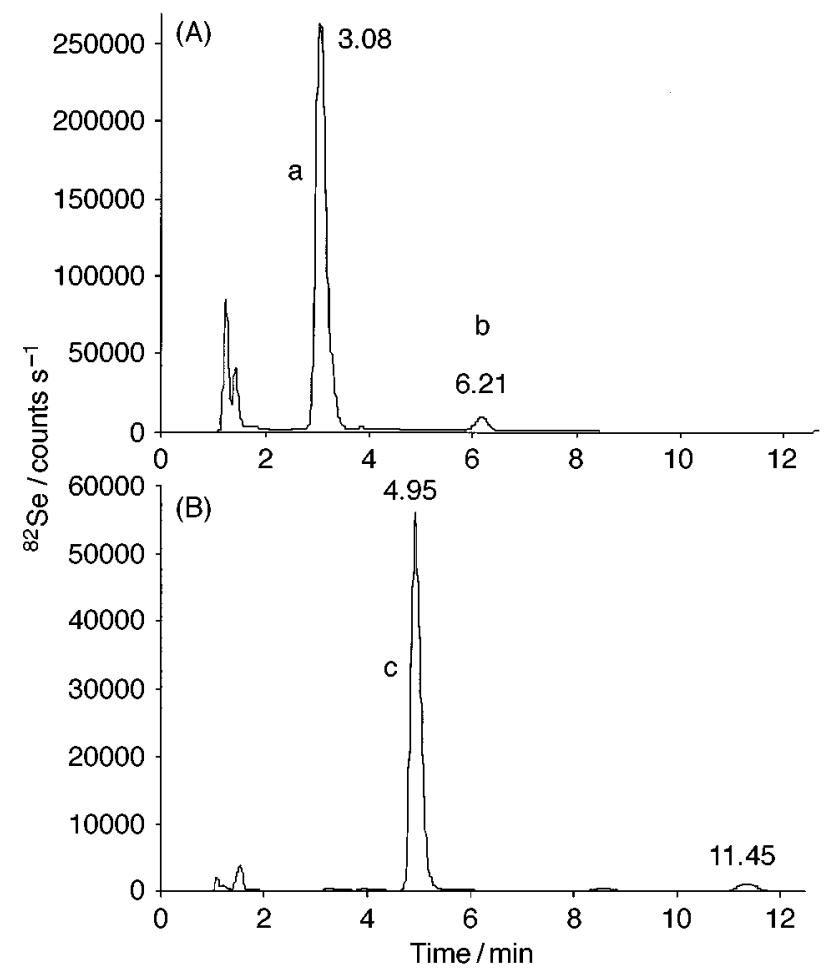

Fig. 1 (A) HPLC-ICP-MS chromatogram of the enzyme digest of selenium-enriched yeast (Nutrition 21) containing $1922 \mu \mathrm{g} \mathrm{g}^{-1}$ total selenium. Identified peaks are: a, selenomethionine and b, Se-adenosylselenohomocysteine. (B) HPLC-ICP-MS chromatogram of the water extract of selenium-enriched garlic containing $296 \mu \mathrm{g} \mathrm{g}^{-1}$ total selenium. The identified peak is c, $\gamma$-glutamyl-Se-methyl-selenocysteine. modified column will be evident in upcoming publications. Since the goal of this work was to identify the later eluting compounds, the low separation efficiency at the beginning of the chromatogram did not represent a problem and was in fact desirable to achieve faster separation.

The yeast analyzed was that used in the now definitive anticarcinogen studies, ${ }^{3}$ which is also commercially available in the form of Selenomax (Nutrition 21) selenium supplement. The total selenium contents of the samples were $1922 \mu \mathrm{g} \mathrm{g}^{-1}$ in the yeast and $296 \mu \mathrm{g} \mathrm{g}^{-1}$ in the garlic. 6,11 The identities of the peaks eluting at 3.08 and $6.21 \mathrm{~min}$ in Fig. 1A and at $4.95 \mathrm{~min}$ (Fig. 1B) were first established by spiking the samples with the appropriate standards. The peaks were identified as selenomethionien, Se-adenosyl-selenohomocysteine and $\gamma$-glutamyl-Semethyl-selenocysteine, respectively. The chromatograms shown in Figs. 1A and B were recorded using the 'regular' 0.2 $\mathrm{g}: 5 \mathrm{~mL}$ sample extracts. The peak at $11.45 \mathrm{~min}$ (Fig. 1B) did not match the retention time of any of our standards.

Comparison of the chromatogram of the yeast's enzymatic digest (Fig. 1A) with its water extract (not shown) showed the absence of the major selenomethionine peak in the water extract, showing that the selenomethionine is covalently bound in proteins. In the water extract Se-adenosyl-selenohomocysteine appeared as the major selenium compound as shown by Casiot et $a l .{ }^{8}$ The then unidentified Se-adenosyl-selenohomocysteine peak was also present in our chromatogram as presented earlier. ${ }^{11}$ The extraction efficiency and column recovery values for the enzymatic digests of yeast were in the range $80-90 \%$, while the hot water extraction efficiency was only approximately $10 \% .^{6,11}$ The two identified compounds account for $82 \%$ of the total selenium compounds eluting from the column after the injection of the enzymatic digest.

Comparison of the chromatogram of the garlic's enzymatic digest (not shown) with its water extract (Fig. 1B) shows no major difference in the peak height of $\gamma$-glutamyl-Se-methylselenocysteine. This indicated that the $\gamma$-glutamyl-Se-methylselenocysteine is not incorporated into proteins. This also supports the suggestion that potentially dangerous accumulation of selenium in body proteins does not occur upon seleniumenriched garlic ingestion, which finding, with the support of animal studies, could be important for choosing which form of selenium supplement would be best. ${ }^{13}$ The efficiency of the hot water extraction was in the range $80-90 \%$ with similar column recovery values, with $\gamma$-glutamyl-Se-methyl-selenocysteine accounting for $85 \%$ of the total selenium compounds eluting from the column.

\section{HPLC-ESI-MS analysis}

All HPLC-ESI-MS analyses were carried out on-line instead of by the heart-cutting method employed by Casiot et al., 8 thus avoiding any possible decomposition of the sample during the preconcentration procedure. Fig. 2 shows the overlaid selected ion chromatograms (SIC) of selenomethionine (3.41 min), $\gamma$ glutamyl-Se-methyl-selenocysteine $(5.07 \mathrm{~min})$ and Se-adenosyl-selenohomocysteine $(6.39 \mathrm{~min})$ at selenium concentrations of 50,20 and $10 \mu \mathrm{g} \mathrm{mL}^{-1}$ The SIC of the three standards were recorded in one injection. The whole mass range $(\mathrm{m} / \mathrm{z}, 50-500)$ was recorded and the SIC's were calculated by the computer after the run was completed. Such an approach gives superior $\mathrm{S} / \mathrm{N}$ ratios compared to total ion chromatograms (TIC). The selenomethionine has molecular ion $\mathrm{M}+1$ at 198 with a loss of 17 , which is attributed to ammonia, producing a fragment ion at mass 181 . The $M+1$ values for $\gamma$-glutamyl-Se-methylselenocysteine and Se-adenosyl-selenohomocysteine are 313 and 433 , respectively. The selenium isotopic pattern is clearly seen in each case.

Fig. 3 shows the SIC of $\mathrm{m} / z=313(5.11 \mathrm{~min})$ and $\mathrm{m} / z=327$ (10.2 min) from 'regular' $(0.2 \mathrm{~g}: 5 \mathrm{~mL})$ and 'concentrated' $(1$ $\mathrm{g}: 5 \mathrm{~mL}$ ) hot water extracts of garlic, respectively. The two SICs were superimposed in one figure. It is necessary to note here that the use of 'concentrated' sample extracts resulted in a 
decrease of the retention times as is shown by comparing those in Fig. 1B (11.45 min) and Fig. 3 (10.12 min) for the same compound. The reason for the shift in retention time was the overloading of the column. The same effect was also observed when the injection volume of the 'regular' extract was increased from 20 to $100 \mu \mathrm{L}$. The mass spectrum of the $5.11 \mathrm{~min}$ peak supports the identification of this peak as $\gamma$-glutamyl-Semethyl-selenocysteine. The peak at 10.12 min was tentatively identified as $\gamma$-glutamyl-Se-selenomethionine based on its molecular weight and the region where it elutes, but this identification needs further proof since a standard to confirm its retention time is not yet available.

Fig. 4 shows the SIC of $\mathrm{m} / z=198$ (3.14 $\mathrm{min})$ and $\mathrm{m} / z=433$ $(6.31 \mathrm{~min})$ from the 'regular' enzymatic digest of seleniumenriched yeast. A similar spectrum can be obtained for the peak eluting at $6.3 \mathrm{~min}$ from the hot water extract of the sample. The mass spectra of the peaks at 3.14 and 6.31 min support the identification of these peaks as selenomethionine and Seadenosyl-selenohomocysteine, respectively, confirming the offline identification of Se-adenosyl-selenohomocystiene in the

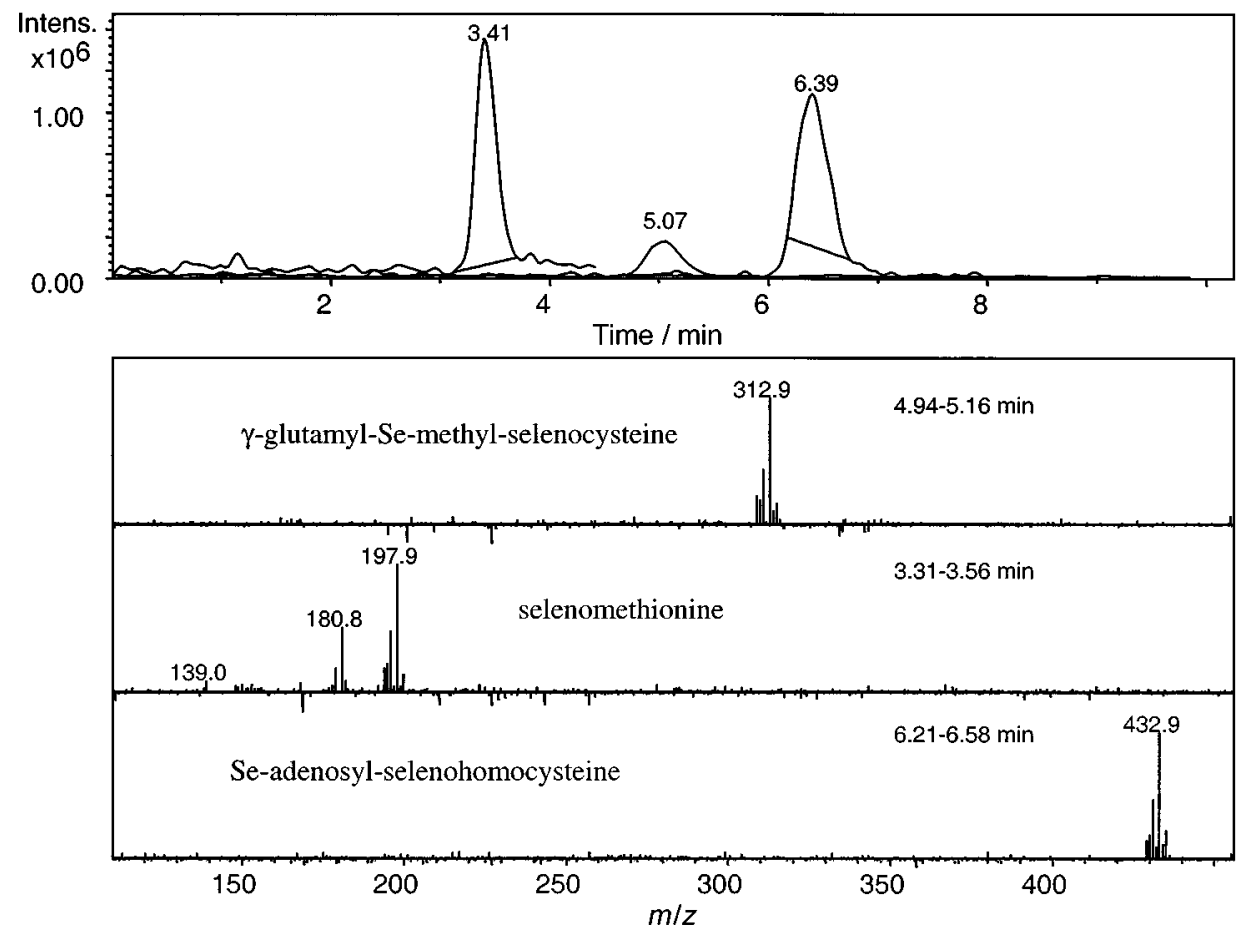

Fig. 2 HPLC-ESI-MS SIC of DL-selenomethionine (3.41 min, $\mathrm{m} / z=198), \gamma$-glutamyl-Se-methyl-selenocysteine $(5.07 \mathrm{~min}, \mathrm{~m} / \mathrm{z}=313)$ and Se-adenosylselenocysteine $(6.39 \mathrm{~min}, \mathrm{~m} / \mathrm{z}=433)$ with concentrations of 50,20 and $10 \mu \mathrm{g} \mathrm{ml}^{-1}$ selenium, respectively, recorded in 3 separate injections and overlaid in one chromatogram.

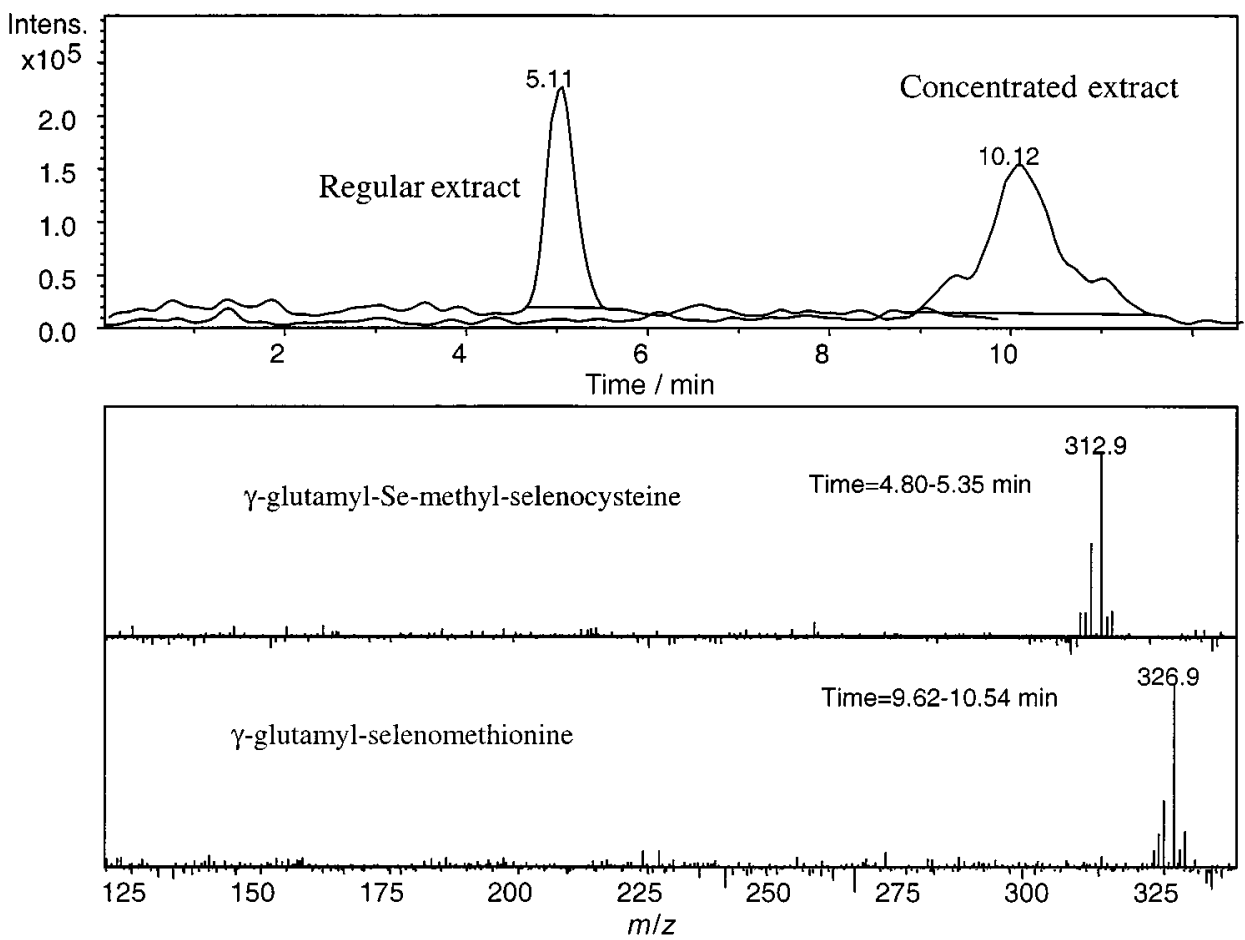

Fig. 3 HPLC-ESI-MS SIC chromatograms of $\mathrm{m} / z=313(5.11 \mathrm{~min})$ and $327(10.12 \mathrm{~min})$ with their spectra from the water extract of selenium-enriched garlic containing $296 \mu \mathrm{g} \mathrm{g}^{-1}$ total selenium. 


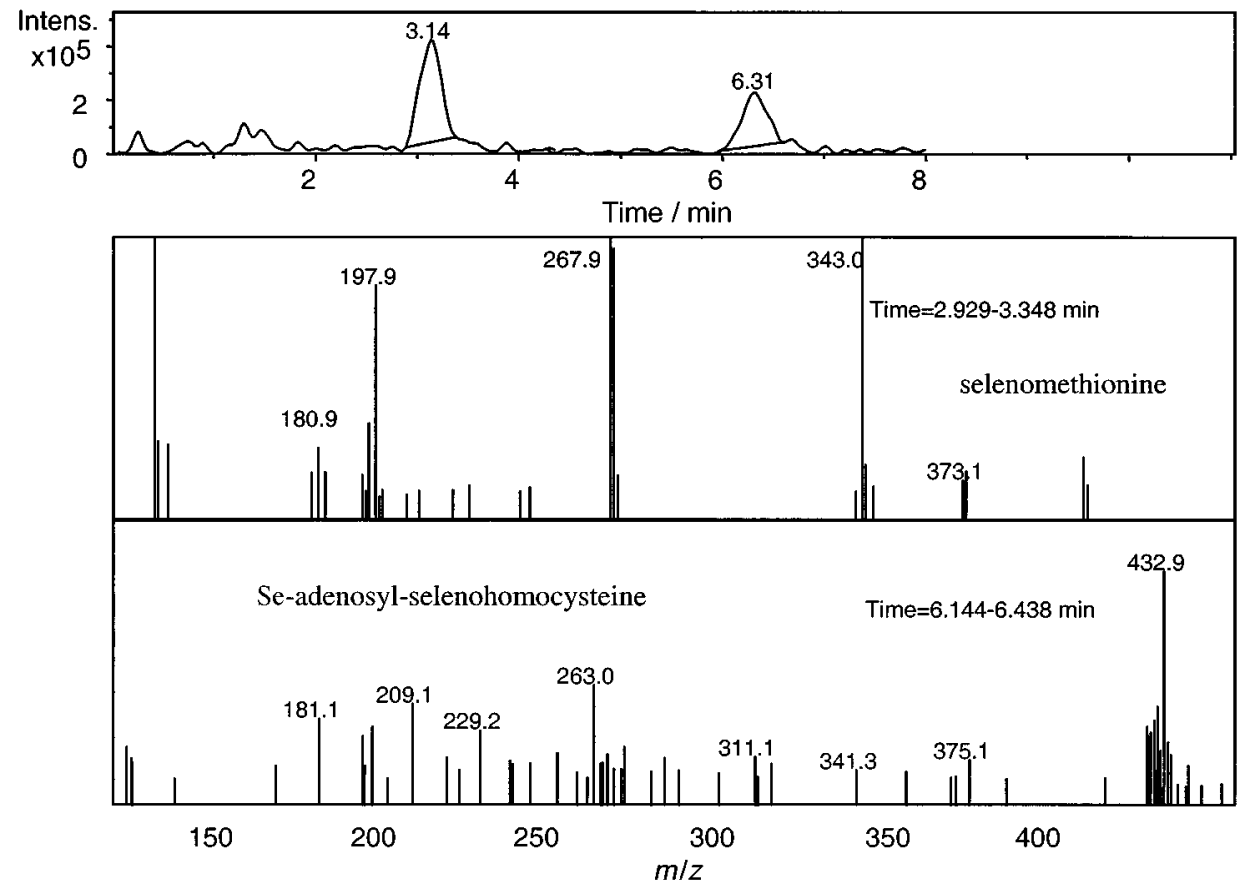

Fig. 4 HPLC-ESI-MS SIC chromatograms of $\mathrm{m} / z=198$ (3.14 min) and 433 (6.31 min) with their spectra from the enzyme digest of selenium-enriched yeast (Nutrition 21) containing $1922 \mu \mathrm{g} \mathrm{g}^{-1}$ total selenium.

water extract. ${ }^{8}$ Peaks observed, in addition to the seleniumcontaining ion $(\mathrm{m} / \mathrm{z}=198)$, in the mass spectrum of selenomethionine in Fig. 4, were from the compounds coeluting with selenomethionine. The $m / z=268$ ion, for example, corresponds to adenosine.

\section{Acknowledgements}

This work was supported in part by the NIH (CA45164) and the NRI Competitive Grants Program/USDA (Award No. 96-355003351). We thank the Schering Plough Research Institute for a fellowship (M.K.). The provision of the Elan 5000 plasma source mass spectrometer by the Perkin-Elmer Corporation, and of the Symmetry Shield RP8 columns by Waters Chromatography Corporation are gratefully acknowledged. Eric Denoyer (Perkin Elmer Corp.) and Ray Crowley (Waters Chromatography Corp.) are thanked for their interest and assistance. The authors also thank John Gray (ETP) for providing the detecting upgrade for the ICP-mass spectrometer.

Any opinions, findings and conclusions or recommendations expressed in this material are those of the authors and do not necessarily reflect the views of the specific granting agency.

\section{References}

1 C. Ip and H. Ganther, in Cancer Chemoprevention, ed. L. Wattenberg, M. Lipkin, C. W. Boone and G. J. Kelloff, CRC Press, Boca Rato, FL, 1992, p. 479.
2 C. Ip, K. Elbayoumy, P. Upadhyaya, H. Ganther, S. Vadhanavikit and H. Thompson, Carcinogenesis, 1994, 15, 187.

3 L. C. Clark, B. W. Turnball, E. H. Slate, D. K. Chalker, J. Chow, L. S. Davis, R. A. Glover, D. K. Graham, E. G. Gross, A. Kongrad, J. L. Lehser, H. K. Park, B. B. Sanders, C. L. Smith, J. R. Taylor, D. S. Alberts, R. J. Allison, J. C. Bradshaw, D. Curtus, D. R. Deal, M. Dellasega, J. D. Hendrix, J. H. Herlong, L. J. Hixon, F. Knight, J. Moore, J. S. Rice, A. I. Rogers, B. Schuman, E. H. Smith and J. C. Woodard, J. Am. Med. Assoc., 1996, 276, 1957.

4 M. A. Quijano, A. M. Gutierrez, M. C. PerezConde and C. Camara, J. Anal. At. Spectrom., 1996, 11, 407.

5 N. Gilon, A. Astruc, M. Astruc and M. Potingautier, Appl. Organomet. Chem., 1995, 9, 623.

6 P. C. Uden, S. M. Bird, M. Kotrebai, P. Nolibos, J. F. Tyson, E. Block and E. Denoyer, Fresenius' J. Anal. Chem., 1998, 362, 447.

7 F. Li, W. Goessler and K. J. Irgolic, J. Chromatogr. A, 1999, 830, 337.

8 C. Casiot, V. Vacchina, H. Chassaigne, J. Szpunar, M. Potin-Gautier and R. Lobinski, Anal. Commun., 1999, 36, 77.

9 G.-M. Momplaisir, L. D. Betowski and W. Winnik, 46th Conference on Mass Spectrometry and Allied Topics, Orlando, FL, 1998, 747.

10 S. M. Bird, H. H. Ge, P. C. Uden, J. F. Tyson, E. Block and E. Denoyer, J. Chromatogr. A, 1997, 789, 349.

11 S. M. Bird, P. C. Uden, J. F. Tyson, E. Block and E. Denoyer, J. Anal. At. Spectrom., 1997, 12, 785.

12 M. Kotrebai, S. M. Bird, J. F. Tyson, E. Block and P. C. Uden, Spectrochem. Acta B., 1999, to be published.

13 C. Ip, personal communication.

14 J. E. Ogara, B. A. Alden, T. H. Walter, J. S. Petersen, C. L. Niederlander and U. D. Neue, Anal. Chem., 1995,67, 3809. 